\title{
Lutetium Lu 177 DOTA-biotin
}

National Cancer Institute

\section{Source}

National Cancer Institute. Lutetium Lu 177 DOTA-biotin. NCI Thesaurus. Code C113801.

A radioconjug ate of biotin conjug ated with the bifunctional, macrocyclic chelating agent tetra-azacyclododecanetetra-acetic acid (DOTA) and labeled with the beta-emitting isotope lutetium Lu 177 (Lu-177) that can be used for radioimmunotherapeutic purposes. Lutetium Lu 177 DOTA-biotin could be used in pre-targeting radioimmunotherapy, which pretreats the lesion with oxidized avidin that binds to protein amino groups on cells. As avidin binds to biotin, the radioisotope can be selectively delivered to cancer cells leading to tumor cell eradication. 